\title{
Endothelial cells in the innate response to allergens and initiation of atopic asthma
}

\author{
Kewal Asosingh, ${ }^{1}$ Kelly Weiss, ${ }^{1}$ Kimberly Queisser, ${ }^{1}$ Nicholas Wanner, ${ }^{1}$ Mei Yin, ${ }^{2}$ Mark Aronica, ${ }^{1,3}$ and Serpil Erzurum ${ }^{1,3}$ \\ 'Department of Inflammation and Immunity, ${ }^{2}$ Imaging Core, Lerner Research Institute, and ${ }^{3}$ Respiratory Institute, the Cleveland Clinic, Cleveland, Ohio, USA.
}

\begin{abstract}
Protease-activated receptor 2 (PAR-2), an airway epithelial pattern recognition receptor (PRR), participates in the genesis of house dust mite-induced (HDM-induced) asthma. Here, we hypothesized that lung endothelial cells and proangiogenic hematopoietic progenitor cells (PACs) that express high levels of PAR-2 contribute to the initiation of atopic asthma. HDM extract (HDME) protease allergens were found deep in the airway mucosa and breaching the endothelial barrier. Lung endothelial cells and PACs released the Th2-promoting cytokines IL-1 $\alpha$ and GM-CSF in response to HDME, and the endothelium had PAC-derived VEGF-C-dependent blood vessel sprouting. Blockade of the angiogenic response by inhibition of VECF-C signaling lessened the development of inflammation and airway remodeling in the HDM model. Reconstitution of the bone marrow in WT mice with PAR-2-deficient bone marrow also reduced airway inflammation and remodeling. Adoptive transfer of PACs that had been exposed to HDME induced angiogenesis and Th2 inflammation with remodeling similar to that induced by allergen challenge. Our findings identify that lung endothelium and PACs in the airway sense allergen and elicit an angiogenic response that is central to the innate nonimmune origins of Th2 inflammation.
\end{abstract}

\section{Introduction}

Asthma is a chronic inflammatory disease of the bronchial tree that is defined by airway wall remodeling, including damage to the airway epithelium, eosinophil infiltration, metaplasia of mucusproducing goblet cells $(1,2)$, and angiogenesis (3-5).

Pattern recognition receptors (PRRs), which recognize structures conserved among infectious agents, also participate in recognition of inhaled allergens and the genesis of atopic asthma (6, 7). PRRs are expressed on professional innate immune cells from the myeloid lineage, including macrophages and dendritic cells, and on nonimmune cells such as epithelial cells, endothelial cells, and fibroblasts. Activation of PRRs on airway epithelial cells and dendritic cells induces signaling cascades, which results in secretion of Th2 cytokines that lead to IgE production, airway hyperresponsiveness, and goblet cell metaplasia $(6,7)$. House dust mite (HDM) allergen protease induces signal transduction by binding to a specific group of $G$ protein-coupled PRRs-the proteaseactivated receptors (PARs) (8-10). PAR-2 is expressed by airway epithelial cells, endothelial and vascular smooth muscle cells, and immune cells in the lungs (8-14). PAR-2 has been implicated in mediating the Th2 response to mucosally administrated allergens $(15,16)$, but it is also important in the angiogenic response $(6,17$, 18). In this context, angiogenic remodeling is a central pathologic process in asthmatic airways $(3,4,19-22)$.

The number of blood vessels in the bronchial wall is highly correlated to severity of asthma (23-25). Accumulating evidence suggests that angiogenesis may be an early step in the genesis of asthma (21, 26-31). In the OVA murine model of allergic airway

Conflict of interest: The authors have declared that no conflict of interest exists. Submitted: September 26, 2017; Accepted: May 1, 2018.

Reference information: / Clin Invest. 2018;128(7):3116-3128.

https://doi.org/10.1172/JCI97720. inflammation, mobilization of proangiogenic hematopoietic progenitor cells (PACs) and angiogenesis occurs as an early response to allergen $(19,20,22,27,28)$. Similar mobilization of PACs are seen in patients with asthma after inhalation of allergen $(22,27)$.

Angiogenic capacity is critically dependent on the VEGFR tyrosine kinase receptors, which have 3 family members: VEGFR1, 2, and 3. Unlike VEGFR1 and 2, VEGFR3 and its ligand VEGF-C are important in new vessel formation $(32,33)$. VEGFR3 is expressed by all endothelia during development but is confined to the lymphatic endothelium after birth (34). However, VEGFR3 is expressed in sprouting new blood vessels in tumors (35-39). Its ligand VEGF-C, derived from proangiogenic macrophages, can induce new vessel branching by stimulating endothelial cell migration and proliferation (40-43). Genetic or pharmacological targeting of VEGFR3 blocks vessel sprouting, reduces vascular density and branching, and decreases endothelial cell proliferation (33).

Based on the importance of angiogenic responses in innate immunity, we hypothesized that inhalational allergens activate PAR-2 on mucosal endothelial cells and PACs, and form an early innate response that promotes the Th2 inflammatory environment of asthma. To test this, we evaluated penetration of HDM extract (HDME) allergens into the airway mucosa, new vessel formation, and release of Th2-promoting cytokines by endothelial cells and PACs in response to HDME. Effects of angiogenesis inhibition on inflammation were studied using molecular and pharmacological approaches in murine models of asthma. Proangiogenic cells conditioned with HDME to activate PAR-2 were adoptively transferred to also evaluate effects on angiogenesis and Th2 inflammation.

\section{Results}

Disruption of the airway epithelial barrier and penetration of allergen into the mucosa following HDME instillation to the airways. Ex vivo experiments with epithelial cell cultures showed that HDM aller- 

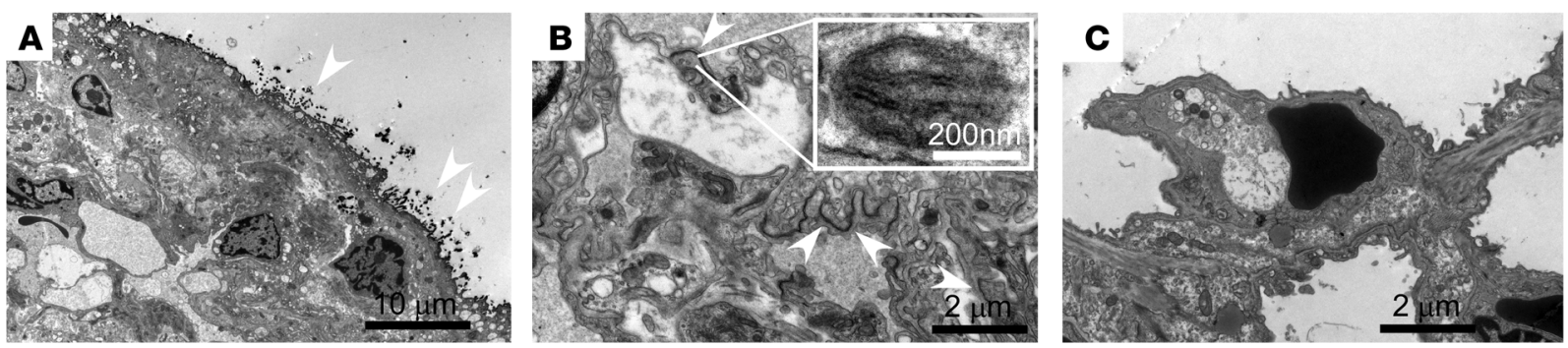

Figure 1. Disruption of lung endothelial barrier by HDME. Naive mice were intranasally challenged with HDME for 4 days followed by a single intranasal dose of HRP (A and B). Animals were euthanized after 24 hours and lungs were harvested and stained with DAB for transmission electron microscopy (TEM). (A) DAB deposits (white arrows, dark dots) were found on the surface of airway epithelium in mice receiving both HDME and HRP. (B) DAB deposits (white arrows) were also observed in the intercellular space of cells forming blood vessel capillaries in the airway mucosa. The presence of Weibel Palade bodies (inset) in these cells confirmed that the cells were endothelial cells. (C) DAB staining was not observed in animals treated with saline.

gen proteases break down the barrier function of airways by cleaving the airway epithelial tight junctions $(44,45)$. We tested whether the impairment of the airway barrier function by HDME in vivo permits penetration of allergens deep into the airway mucosa. HDME was instilled into the airways of naive mice once daily for 4 days. Disrupted tight junctions were visualized using HRP, which was instilled into the airways of living mice 24 hours after the final HDME instillation. The electron-dense DAB-positive staining of HRP was seen within the mucosa beneath the epithelium (Figure 1, A and B). Animals treated with saline instead of HDME did not show mucosal DAB staining (Figure 1C). Disruption was also confirmed by intranasal delivery of low-molecular-weight dextran to mice at 19 hours after the last HDME instillation. Dextran was found in the blood circulation at levels 5 times higher in HDME mice compared with naive mice $(70 \mu \mathrm{g}$ dextran $/ \mathrm{ml}$ serum $\pm 8 \mu \mathrm{g}$ dextran $/ \mathrm{ml}$ serum in mice receiving HDME plus dextran; 6 $\mu \mathrm{g}$ dextran $/ \mathrm{ml}$ serum $\pm 0.1 \mu \mathrm{g}$ dextran $/ \mathrm{ml}$ serum in mice receiving HDME plus saline; $12 \mu \mathrm{g}$ dextran $/ \mathrm{ml}$ serum $\pm 6 \mu \mathrm{g}$ dextran $/ \mathrm{ml}$ serum in naive mice receiving dextran; $P<0.0001$ by ANOVA). There was no significant difference in blood dextran concentration between nasal and pharyngeal HDME administration, indicating that disruption of the nasal epithelial barrier did not significantly contribute to the higher levels in the circulation (nasal: 68 $\mu \mathrm{g}$ dextran $/ \mathrm{ml}$ serum $\pm 10 \mu \mathrm{g}$ dextran $/ \mathrm{ml}$ serum in mice receiving HDME plus dextran; pharyngeal: $80 \mu \mathrm{g}$ dextran $/ \mathrm{ml}$ serum $\pm 11 \mu \mathrm{g}$ dextran $/ \mathrm{ml}$ serum in mice receiving HDME plus dextran; $P<0.32$ by Student's $t$ test). HDM allergen Der $\mathrm{p} 1$ quantification by ELISA in plasma obtained from the left atrium demonstrated the presence of the allergen in the lung circulation $(164 \mathrm{ng} / \mathrm{ml}$ plasma \pm $0.65 \mathrm{ng} / \mathrm{ml}$ plasma in mice receiving HDME; $0 \mathrm{ng} / \mathrm{ml}$ plasma \pm 0 $\mathrm{ng} / \mathrm{ml}$ plasma in mice receiving saline; $P<0.0001$ by Student's $t$ test). These data are consistent with a prior report in which epithelial cell permeability of cell cultures exposed to HDM protease was measured using mannitol isotope and disrupted tight junctions visualized using fluorescence microscopy (45). Based on these data, endothelial activation was evaluated in response to allergen.
Figure 2. Expression of PAR-2 by lung endothelial cells and production of Th2-promoting cytokines. (A) Lungs were harvested from naive mice and digested into a single-cell suspension for flow cytometric analysis. Gating strategy for endothelial cells is shown. Endothelial cells were further subgrouped into lymphatic endothelial cells and blood vessel endothelial cells and analyzed for PAR-2 expression. Gray histograms represent samples stained for the full panel without PAR-2 primary antibody. (B and C) Lung endothelial cells isolated from naive mice were incubated with or without HDME for 5 days, and GM-CSF and IL-1 $\alpha$ were analyzed in the supernatant. Mean \pm SE values of 5 mice are shown. Two-tailed Student's $t$ test was used.

A

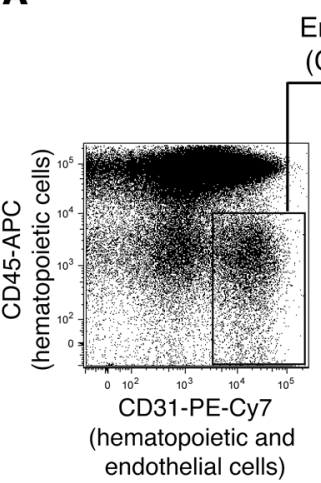

Endothelial cells

Blood vessel (CD31+ CD45-)

endothelial cells (CD31+ CD45- CD90-) endothelial cells (CD31+ CD45- CD90
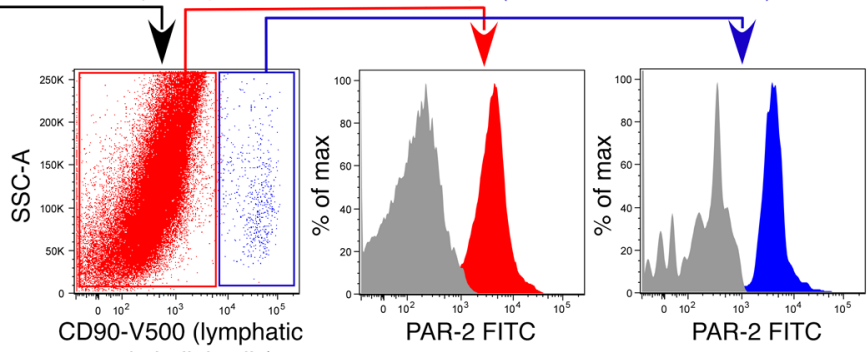

endothelial cells)

B

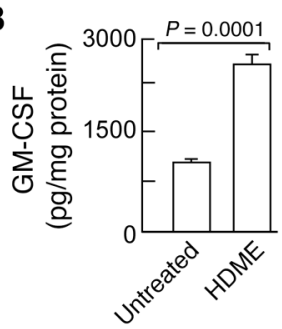

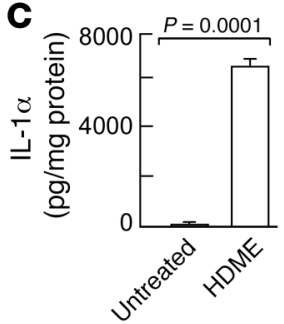



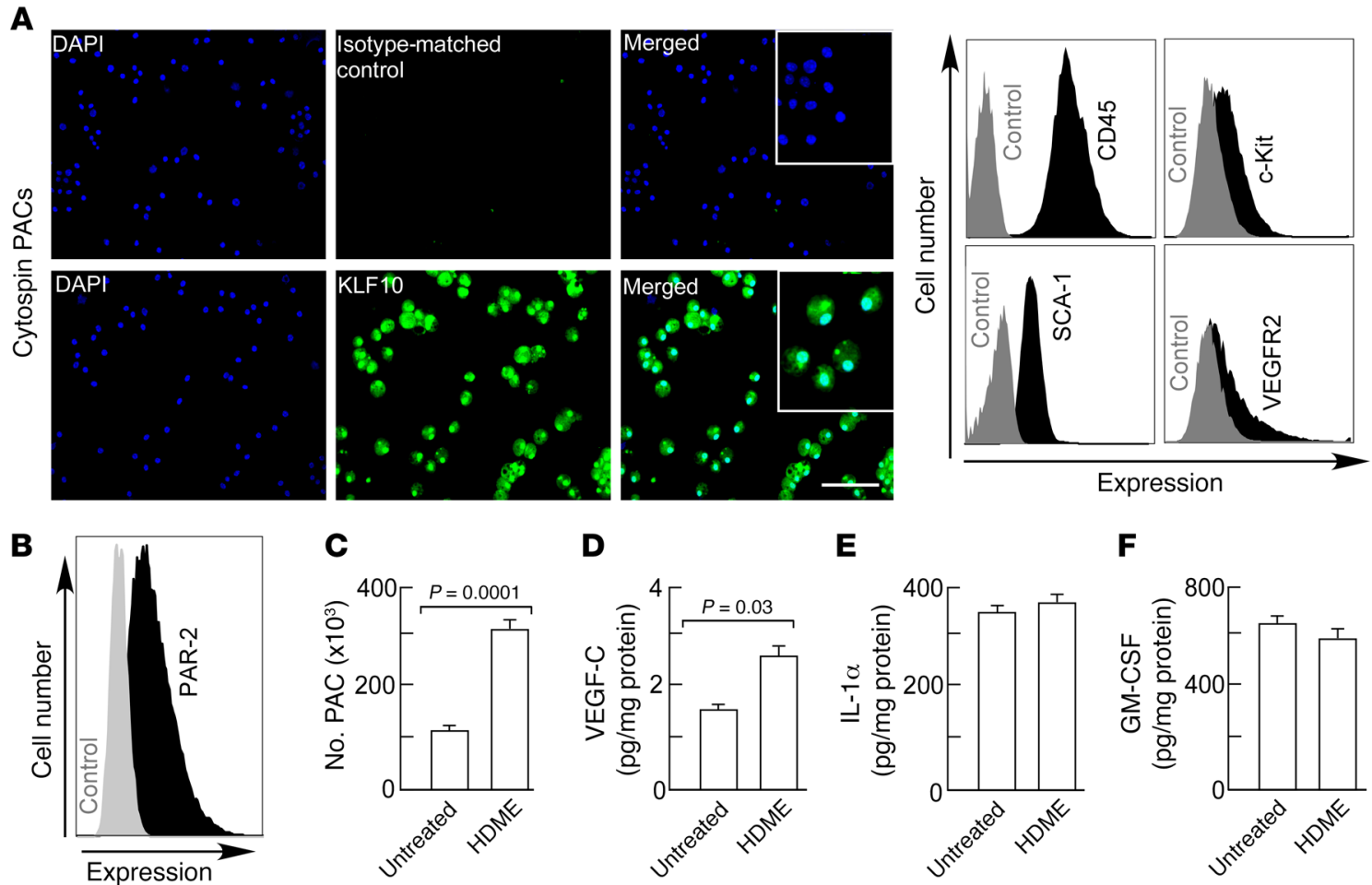

C

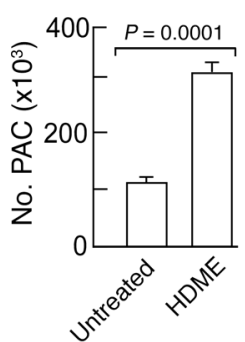

D

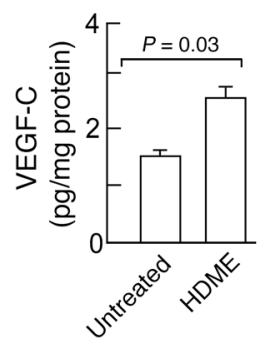

E

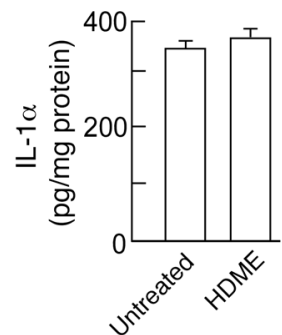

$\mathbf{F}$

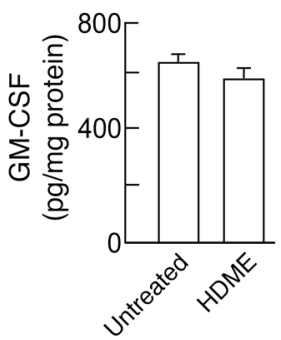

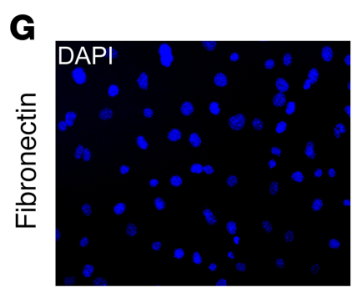
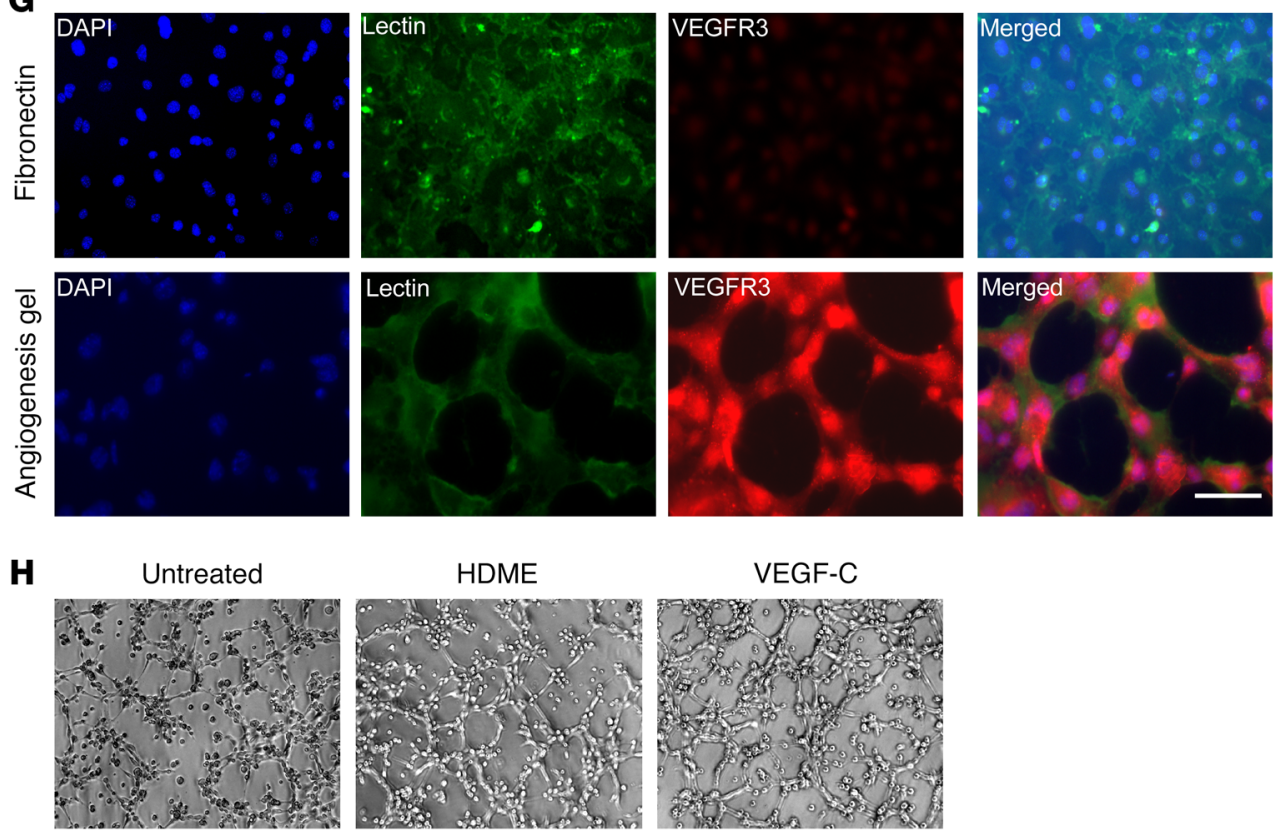

VEGF-C
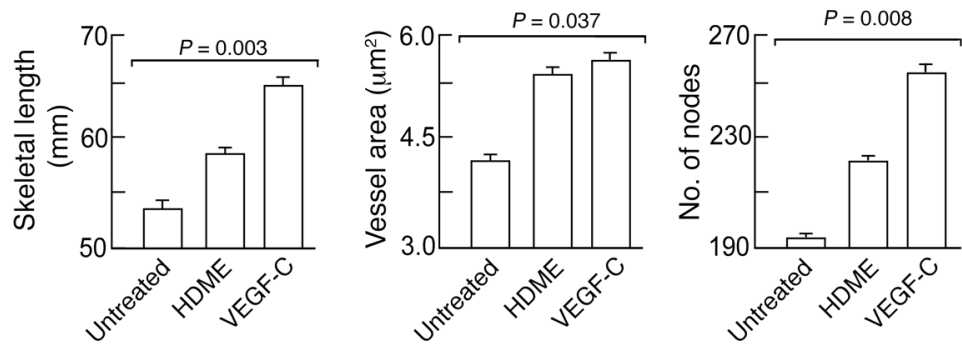
Figure 3. Th2-promoting and angiogenic cytokine production by PACs. (A) Expression of transcription factor KLF10, C-Kit, SCA-1, and VEGFR2 by hematopoietic progenitor cells during differentiation into PACs. Black histograms show expression of the respective markers and gray histograms represent staining without primary antibody. Inset shows high power images, illustrating nuclear expression. Stainings were performed on cytospins of PACs. Scale bar, $100 \mu \mathrm{m}$. (B) Flow cytometric analysis of PAR-2 expression. Black histograms show expression of PAR-2 and gray histograms represent staining with secondary antibody only. (C) HDME-induced PAC proliferation. (D-F) HDME-induced VEGF-C, IL-1 $\alpha$, and GM-CSF secretion. PACs were exposed to HDME for 5 days. IL-1 $\alpha$, VEGF-C, and GM-CSF secretion in the supernatant was measured by ELISA. Mean \pm SE values of $n=4$ mice are shown. (C) Lung endothelial cells were cultured on fibronectin or an angiogenesis gel and stained for lectin (endothelial cell marker) and VEGFR3. Scale bar, $100 \mu \mathrm{m}$. (H) Lung endothelial cells were seeded on an angiogenesis gel and exposed to HDME or VEGF-C to analyze angiogenic tube formation. Tube skeletal length, vessel area, and number of nodes were quantified. All fluorescence flow cytometry data are expressed on log scales. Mean \pm SE values of 4 experiments are shown. Two-tailed Student's $t$ test was used in $\mathbf{C}, \mathbf{D}$, and $\mathbf{E}$. ANOVA test was used in $\mathbf{H}$.

PAR-2 activation of endothelial cells and PACs by HDME lead to Th2 cytokines and angiogenesis. First, expression of PAR-2 was evaluated on lung endothelial cells. Lungs from naive mice were harvested, enzymatically digested into single-cell suspension, and analyzed for number of endothelial cells by flow cytometry (19). Blood vessel and lymphatic vessel endothelial cells were discriminated based on the expression of CD90 (46). Blood and lymphatic vessel endothelial cells expressed PAR-2 (Figure 2A). Next, the lung endothelial cells were isolated $(19,20)$ and exposed to HDME ex vivo. Lung endothelial cells produced and secreted the Th2-promoting cytokines GM-CSF and IL- $1 \alpha$ at baseline, and production was markedly increased after HDME exposure (Figure 2, B and C). VEGF-C secretion by lung endothelial cells was below the detection limit $(<5 \mathrm{pg} / \mathrm{ml})$ (data not shown). To assess whether PACs expressed PAR-2, PACs were isolated from the bone marrow as previously described (19), and identification was confirmed by staining for nuclear expression of the transcription factor Krüppellike factor 10 (KLF10) (47, 48) (Figure 3A). In the bone marrow, KLF10 is specifically expressed by myeloid progenitors differentiating into PACs (48). The cells were also positive for the traditional PAC markers c-Kit, SCA-1, and VEGFR2, in addition to CD45 (49) (Figure 3A). Naive PACs expressed PAR-2 (Figure 3B). HDME exposure of PACs caused cell proliferation as indicated by higher cell numbers (Figure 3C) and increased staining for proliferation marker Ki-67 (3.8\% $\pm 0.04 \%$ in saline-exposed PACs; $5.5 \% \pm 0.6 \%$ in HDME-exposed PACs; $P=0.048$ by Student's $t$ test). Secretion of angiogenic factor VEGF-C was also increased $(21 \mathrm{pg} / \mathrm{ml} \pm 3 \mathrm{pg} /$ $\mathrm{ml}$ in saline-exposed PACs; $34 \mathrm{pg} / \mathrm{ml} \pm 3 \mathrm{pg} / \mathrm{ml}$ in HDME-exposed PACs; $P<0.03$ ) (Figure 3D). PACs expressed IL-1 $\alpha$ and GM-CSF, and the secretion was not increased by HDME exposure (Figure 3, $\mathrm{E}$ and $\mathrm{F})$. HDME exposure also resulted in mobilization of PAR-2expressing PACs in vivo (PAR-2+VEGFR2 ${ }^{+}$SCA- $1^{+}{ }^{+}-\mathrm{Kit}^{+}$: 98 cells/ $\mu \mathrm{l}$ blood \pm 5.3 cells $/ \mu$ l blood in HDME-exposed mice; 44 cells $/ \mu 1$ blood \pm 6.5 cells $/ \mu$ l blood in saline-exposed mice; $P<0.002$ by Student's $t$ test). To determine if an allergen induced a proangiogenic endothelial phenotype, tube formation was measured using lung endothelial cells seeded on an angiogenesis gel. In angio- genesis assays using the gel matrix, cells expressed VEGFR3 (Figure 3G) and made tubes. Angiogenic capacity, as measured by tube length, total endothelial tube area, and number of nodes, was the highest in endothelial cells exposed to VEGF-C (Figure $3 \mathrm{H})$. Exposure of the endothelial cells to HDME, which activates PAR-2, induced some sprouting as indicated by increased endothelial vessel area, consistent with the literature $(17,18)$. However, HDME induced organization of the cells to form continued skeletal-length tubes, and tube branching (number of nodes) was less compared with VEGF-C (skeletal length: $58 \mathrm{~mm} \pm 0.3 \mathrm{~mm}$ HDME, $64 \mathrm{~mm} \pm 1.5 \mathrm{~mm}$ VEGF-C, $P<0.02$ by Student's $t$ test; number of nodes: $220 \pm 5 \mathrm{HDME}, 253 \pm 12 \mathrm{VEGF}-\mathrm{C}, P<0.01$ by Student's $t$ test). Overall, these experiments show that HDME can activate Th2-promoting angiogenic microenvironment by directly activating PACs and endothelial cells.

Blocking angiogenesis by pharmacological inhibition of VEGFR3 kinase attenuates airway inflammation and remodeling. VEGFR3 is a newly identified target for angiogenesis in pathological conditions such as tumor growth and macular degeneration $(33,50)$. Based on the observation of VEGFR3 expression by lung endothelial cells after HDME exposure and secretion of its ligand VEGF-C by HDME-exposed PACs, we investigated whether blocking VEGFR3 might blunt angiogenesis and airway inflammation in the HDM murine asthma model, which is typified by all the characteristics of asthma, including angiogenesis (51-53). Deletion of the VEGFR3 gene is lethal, so VEGFR3 was inhibited by intraperitoneal VEGFR3 kinase inhibitor MAZ51 $(33,50,54)$. Control groups included HDME-exposed animals treated with vehicle in place of MAZ51 and mice exposed to saline in place of HDME. Flow cytometric analysis of whole-lung, single-cell suspensions obtained from animals exposed to HDME showed that the expression of VEGFR3 on hematopoietic cells was rare (VEGFR3 ${ }^{+}$cells among CD $45^{+}$cells: $\left.0.08 \% \pm 0.02 \%\right)$. The vast majority of VEGFR3expressing cells was located in the nonhematopoietic (CD45-) fraction (Figure 4A), and immunohistochemical analyses confirmed that VEGFR3 was expressed by blood vessel endothelial cells (Figure 4A). VEGFR3 expression on blood vessel endothelial cells in vivo was increased in HDME-exposed mice (Figure 4A). Flow cytometric analysis showed increased endothelial cell proliferation in HDME-exposed lungs (Ki-67 endothelial cells: $0.50 \% \pm$ $0.04 \%$ in saline-exposed lungs; $2.0 \% \pm 0.3 \%$ in HDME-exposed lungs; $P<0.01$ by Student's $t$ test). HDME exposure increased angiogenesis but not lymphangiogenesis (Figure 4, B and C), in line with a previous report (46). The number of blood vessel endothelial cells expressing PAR-2 was significantly reduced in mice treated with MAZ51 (Figure 4D). The recruitment of PACs into the lungs was suppressed by blocking VEGFR3 (Figure 4E). The reduction of angiogenic responses was associated with decreased mucus cell metaplasia and airway inflammation (Figure 4F). The Th2 cytokines IL-4, IL-13, and IL-5 in the bronchoalveolar lavage fluid (BAL) of animals treated with MAZ51 were also decreased, as was airway hyperreactivity (Figure 4G). The findings show that VEGFR3 contributes to HDME-induced angiogenesis and airway inflammation, remodeling, and hyperreactivity.

Bone marrow PAR-2 and KLF1O expression contributes to HDMEinduced airway inflammation and remodeling. In the experiment described above, endothelial cells were blocked, and in this experi- 
A
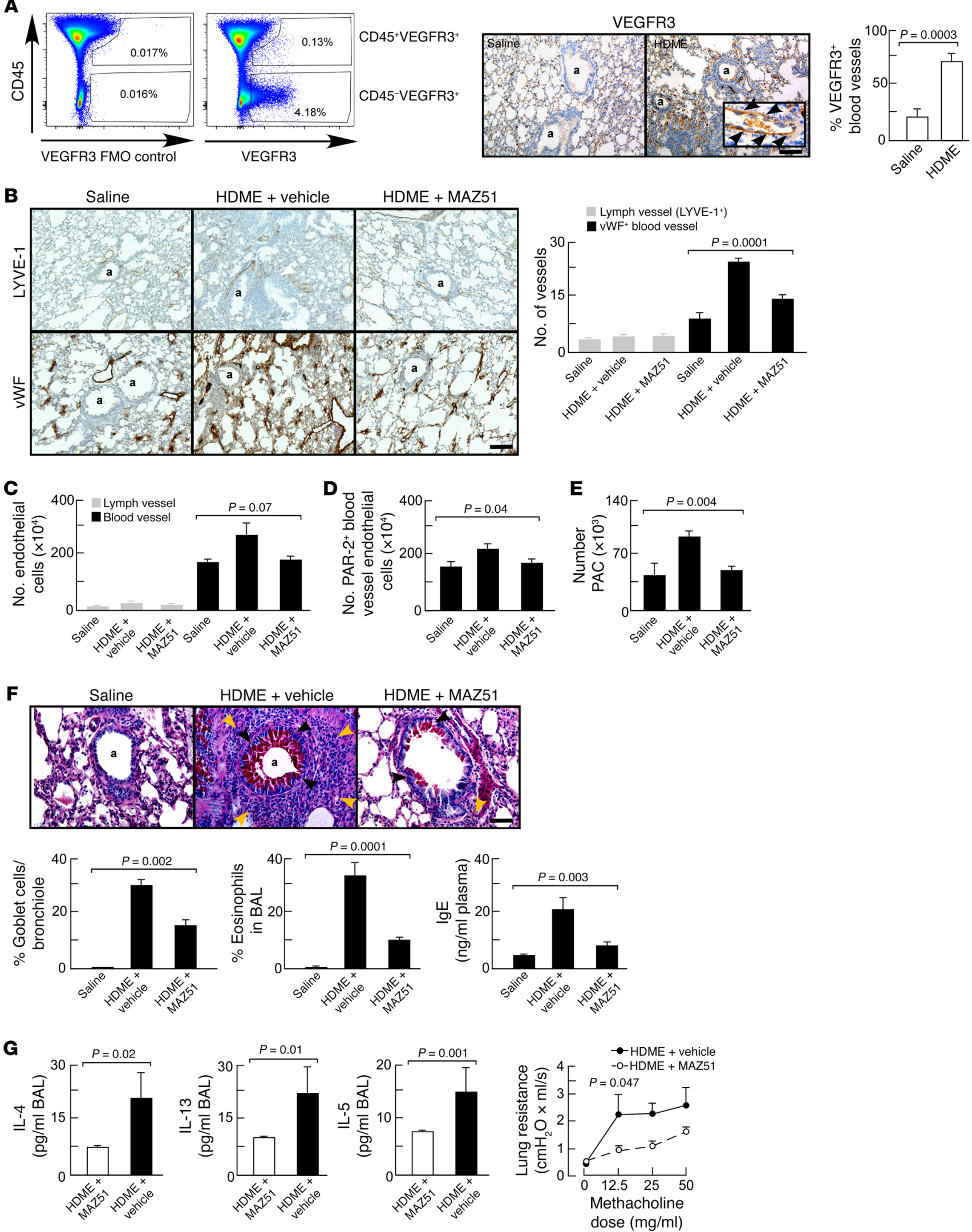
Figure 4. Inhibition of pathological angiogenesis by VEGFR3 kinase inhibitor reduced airway inflammation, remodeling, and hyperreactivity. (A) Flow cytometric analysis of VEGFR3 expression among hematopoietic (CD45') and nonhematopoietic (CD45') lung cells. Immunohistochemical analysis of VEGFR3 expression on blood vessel endothelial cells (vessels with red blood cells) showed that VEGFR3 expression is upregulated on blood vessel endothelial cells in the HDM model. Scale bar, $200 \mu \mathrm{m}$. Original magnification for inset is $\times 400$. (B) Treatment with VEGFR3 kinase inhibitor MAZ51 decreased angiogenesis (VWF' blood vessel) density, but not lymphangiogenesis (LYVE-1+ vessels). Data are mean $\pm \mathrm{SE}$ values of 4-5 mice in each group. The number of vessels per $2,500 \mu \mathrm{m}^{2}$ area is shown. Scale bar, $400 \mu \mathrm{m}$. (C) Treatment with VEGFR3 kinase inhibitor MAZ51 tended to reduce the number of total blood vessel endothelial cells. (D) The number of PAR-2+ blood vessel endothelial cells was significantly lower in asthmatic mice treated with MAZ51. (E) The recruitment of PACs into the lungs was reduced by MAZ51. (F) The number of mucus-producing cells (black arrows) and (eosinophilic) inflammation (brown arrows) were significantly lower in mice treated with MAZ51. Scale bar, $100 \mu \mathrm{m}$. (C) Th2 cytokines and airway hyperreactivity were reduced in animals treated with MAZ51. Mean \pm SE values of 4-5 mice in each group are shown. Two-tailed Student's $t$ test was used in $\mathbf{A}$ and $\mathbf{G}$. ANOVA test was used in B, C, and $\mathbf{F}$. A linear regression model was used to compare lung resistance in $\mathbf{G}$. The interaction between group and methacholine dose in the linear mixed effects model for log-transformed values demonstrates that there are differing slopes describing the relationships between methacholine and Rrs for the DMSO and MAZ51 groups $(P=0.047)$. The estimated slope was 0.039 (95\% Cl 0.026-0.053) for DMSO and 0.023 (95\% Cl 0.010-0.037) for MAZ51, indicating a greater change in Rrs in response to methacholine for the DMSO group. In A, $\mathbf{B}$, and $\mathbf{F}$, a indicates airway.

ment PACs were targeted. Based on the finding that PACs highly express KLF10 and PAR-2, both critical in angiogenesis (17, 18, $47,48,55,56)$, we tested if these pathways in PACs contributed to HDME-induced angiogenesis and airway inflammation. Flow cytometric analysis showed that animals transplanted with $\mathrm{KLF}^{-1}$ or PAR-2 ${ }^{-/}$bone marrow exhibited a significantly reduced number of PAR- $2^{+}$blood vessel endothelial cells (Figure $5 \mathrm{~A}$ ). Blood vessel density, but not lymphatic vessel density, was reduced in recipients of $\mathrm{KLF} \mathrm{O}^{-/-}$or PAR-2 ${ }^{-/-}$bone marrow exposed to HDME (Figure 5B). Mucus cell metaplasia and airway inflammation were also reduced in $\mathrm{KLF}^{-/-}$or PAR-2 ${ }^{-/-}$bone marrow chimera (Figure $5 \mathrm{C})$. Airway hyperreactivity was higher in mice engrafted with WT bone marrow compared with recipients of $\mathrm{KLF}^{-/-}$or $\mathrm{PAR}-2^{-/-}$at

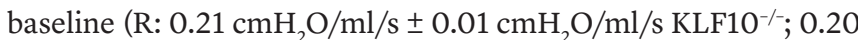
$\mathrm{cmH}_{2} \mathrm{O} / \mathrm{ml} / \mathrm{s} \pm 0.01 \mathrm{cmH}_{2} \mathrm{O} / \mathrm{ml} \mathrm{PAR}^{-2 /-} ; 0.27 \mathrm{cmH}_{2} \mathrm{O} / \mathrm{ml} / \mathrm{s} \pm 0.01$ $\mathrm{cmH}_{2} \mathrm{O} / \mathrm{ml} / \mathrm{s} \mathrm{WT} ; \mathrm{P}<0.003$ by ANOVA). No significant differences were observed with methacholine challenge. The findings show that PACs and bone marrow PAR-2 expression are important contributors to HDME-induced airway inflammation and remodeling.

Intravenous adoptive transfer of HDME-exposed PACs is sufficient to induce pathological angiogenesis and airway inflammation, remodeling, and hyperreactivity. To test whether PACs are sufficient for HDME-induced asthma, ex vivo HDME-exposed PACs were adoptively transferred into mice. Mice were intranasally sensitized with HDME and the daily challenge with HDME 1 week after sensitization was replaced by daily intravenous adoptive transfer of PACs (Figure 6A). For this purpose, PACs were isolated from naive mice and exposed to HDME or saline ex vivo, followed by intravenous injection into mice that were previously intranasally sensitized with HDME. Recipients of HDME-exposed PACs exhibited increased angiogenesis compared with mice injected with saline-exposed PACs (Figure 6B). Lymphangiogenesis was similar between the groups (Figure 6B). Adoptive transfer of HDME-exposed PACs, but not naive PACs, increased the number of PAR-2 ${ }^{+}$and $\mathrm{VEGFR}^{+}$endothelial cells in the lungs (Figure 6C). Adoptive transfer of HDME-exposed bone marrow cells depleted of PACs (SCA-1 ${ }^{-}$cells) did not cause an increase in PAR-2 or VEGFR3 expression in lung endothelial cells (PAR-2+ endothelial cells: $18.3 \% \pm 2.2 \%$ in HDME-exposed SCA-1 ${ }^{-}$cells, $14.4 \% \pm$ $1.1 \%$ in saline-exposed PACs, $P<0.15$; VEGFR3 ${ }^{+}: 33.6 \% \pm 2.3 \%$ in HDME-exposed SCA-1 ${ }^{-}$cells, $33.7 \% \pm 1.8 \%$ in saline-exposed PACs, $P=0.98$ ). The increase of innate receptors in recipients of HDME-exposed PACs was accompanied by increased mucus cell metaplasia and airway inflammation (Figure 6D). Analysis of BAL showed that adoptive transfer of PACs exposed to HDME but not saline increased the Th2 cytokines IL-4, IL-13, and IL-5 in the lungs. Moreover, animals receiving HDME-exposed PACs developed airway hyperreactivity (Figure 6E).

Overall, the findings clearly show that HDME-exposed PACs in animals sensitized to HDME is sufficient to induce airway inflammation, remodeling, and hyperreactivity, without allergen challenge.

\section{Discussion}

The endothelium has been likened to an inner epithelium, serving as a second line of physical boundary against external pathogens (57-59). Aberrant endothelium in asthma has been recognized for more than a century (3). Historical landmark studies of resected lungs and bronchial biopsies reported increased airway vascularity in asthmatic lungs $(3,4)$ as one of the most consistent characteristics of asthma remodeling, occurring in mildly, moderately, and severely asthmatic lungs $(23-25,60)$. In humans, where there is clear compartmentalization of bronchial and pulmonary circulations (31), asthma-associated angiogenesis is limited to the bronchial wall; in mice, which have a less-well-defined bronchial circulation, angiogenesis occurs in the whole lung with asthma models (26).

PAR-2 may serve as a common mechanism for the pathogenesis of inflammation and angiogenesis in asthma. The role of airway epithelial PAR-2 in asthma is well-established $(6,7)$. In the HDM model, PAR-2 is required for airway inflammation via induction of airway epithelial IL-1 $\alpha$ and GM-CSF $(8,61,62)$. Overexpression of PAR-2 in mice results in greater eosinophilic airway inflammation, IgE levels, and airway hyperreactivity in mice sensitized and challenged with OVA, a model of atopic asthma. In contrast, PAR-2 knockdown in mice reduces eosinophil infiltration, IgE levels, and airway hyperreactivity in the OVA model (63). In addition to its role in inflammatory responses, activation of PAR-2 promotes endothelial cell proliferation, and recruitment of myeloid proangiogenic cells leads to angiogenesis (6). For example, tumor angiogenesis, angiogenesis in wound healing, and hypoxia-induced angiogenesis are PAR-2 dependent, evidenced by diminished angiogenesis in PAR-2-deficient mice $(17,18)$. Likewise, in hind limb ischemia and retinal angiogenesis models, PAR-2 agonists induce endothelial cell proliferation and enhance the angiogenic response $(55,56)$.

Here, HDM protease allergens are shown to penetrate the airway mucosa and activate PAR-2 on endothelial cells and PACs, which triggers an innate Th2-promoting angiogenic response in asthma (Figure 7). HDM allergens breach epithelium and endo- 
A

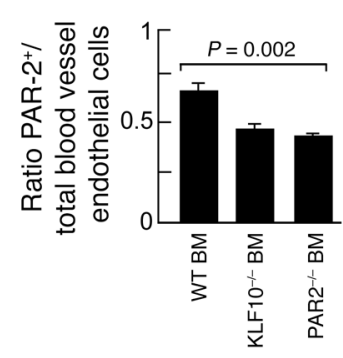

B

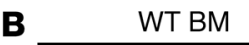

亡े

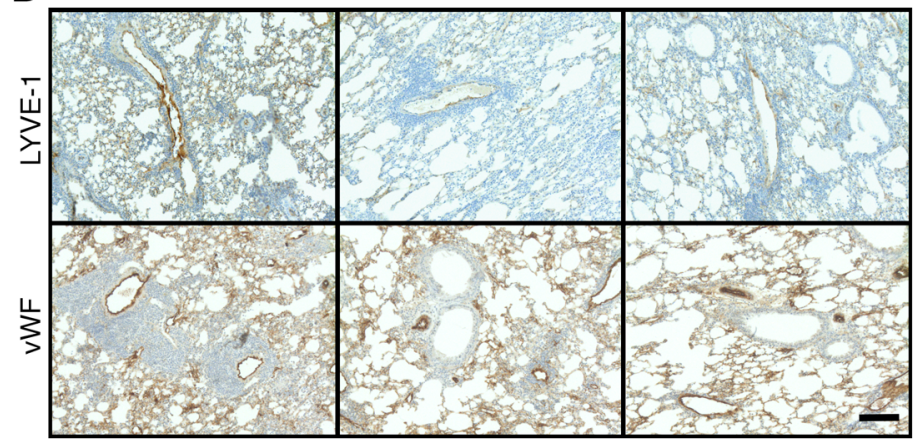

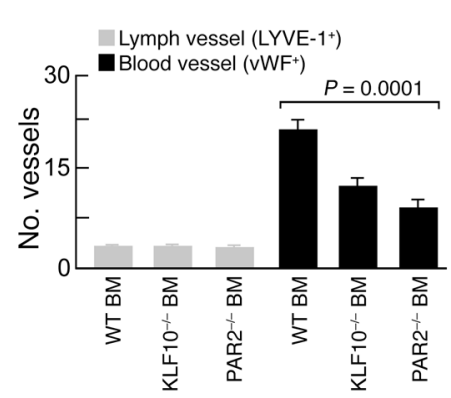
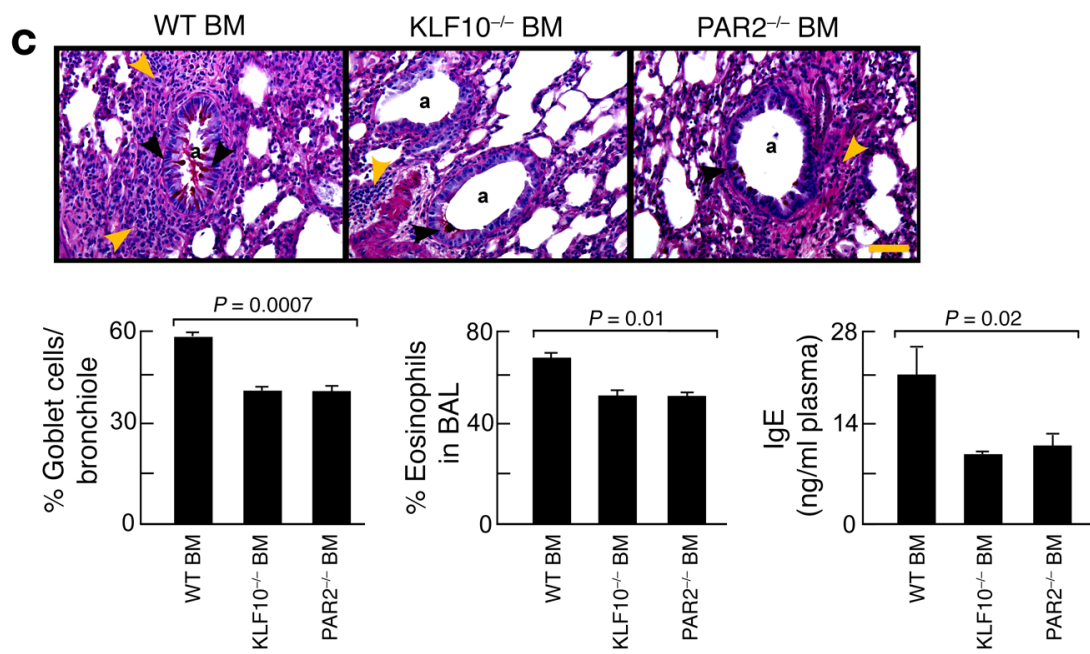

Figure 5. Pathological angiogenesis and airway inflammation blocked by KLF10-deficient or PAR-2-deficient bone marrow transplantation. (A) KLF10-/or PAR-2-/- bone marrow transplantation in WT mice inhibited pathological angiogenesis in the HDM model. (B) Blood vessel density, but not lymphatic vessel density, was decreased in KLF10 ${ }^{-1-}$ or PAR-2 $2^{-/-}$recipients. The number of vessels per $2,500 \mu \mathrm{m}^{2}$ area is shown. Scale bar, $400 \mu \mathrm{m}$. (C) The number of mucus-producing cells (black arrows), (eosinophilic) inflammation (brown arrow), and IgE levels were significantly lower in KLF10 $0^{-1-}$ or PAR-2 $2^{-1-}$ bone marrow chimera. Scale bar, $100 \mu \mathrm{m}$. Lowercase a indicates airway. Mean \pm SE values of 4 mice in each group are shown. ANOVA test was used in all panels.

thelium barriers, consistent with a human study reporting the presence of HDM allergens in amniotic fluid, maternal blood, and umbilical cord blood (64). PACs have established roles in asthma $(19,20,22,27,28)$ and are derived from hematopoietic stem/progenitor cells predominantly committed to the myeloid lineage (49, 65). Historically, these cells have been classified as "endothelial progenitor cells." However, recent evidence has identified their origin from hematopoietic stem cells (49). PACs express both hematopoietic progenitor and endothelial cell antigens and lack dendritic cell or innate type 2 lymphoid markers (22), and their angiogenic activity is mainly attributable to the release of potent paracrine angiogenic factors (49). The exact differentiation pathway of hematopoietic stem/progenitors to PACs is unclear, but several lines of evidence suggest KLF10 is involved in the activation of their angiogenic differentiation $(47,65)$. For example, mice deficient in KLF1O have severe impairment of hematopoietic stem cell differentiation to PACs and fail to recover from hind leg ischemia due to impaired vascularization capacity (47).

Disruption of the endothelial barrier in the airway mucosa likely also contributes to the thickening of the airway wall. Leaky blood vessels are a major cause of airway edema $(66,67)$. Allergen proteases may directly contribute to airway edema by locally modifying vascular permeability, allowing fluid and small molecules to move freely between plasma and interstitial fluid. VEGFR 3 is important in tracheal lymphangiogenesis as shown in a mouse model of chronic inflammation caused by infection with mycoplasma pulmonis, a microorganism that can exaggerate asthma exacerbations (68). In this model, VEGF-C induced leaky lymphatic vessels but did not affect tracheal angiogenesis, suggesting that VEGFR3 expression may be restricted to specific areas of the airways. In another report, lymphangiogenesis was observed in a rat model of chronic (3 weeks) high-dose (100 $\mu \mathrm{g} / \mathrm{challenge)} \mathrm{HDME} \mathrm{exposure} \mathrm{(69).} \mathrm{In} \mathrm{line}$ with a previous report (46), we did not observe lymphangiogenesis in the standard mouse model of HDM-induced asthma. The findings from the mouse mycoplasma pulmonis and rat model suggest that lymphangiogenesis may occur in chronic allergic asthma or asthma exaggerated by an infectious insult. Another explanation is that there may be differences in lymphangiogenesis between mouse and rat models. VEGFR3 was not expressed by PACs (not shown) and VEGFR3 expression by immune cells in the lungs was rare, consistent with a previous report that bone marrow hematopoietic cells, including stem/progenitor cells, are negative for VEGFR3 (70). In the eye however, expression of VEGFR3 by retinal macrophages and corneal dendritic cells has been demonstrated 
$(43,71)$. Other studies have shown rapid release of PAC chemoattractants, such as CXCR2 and CXCR4 agonists, within 24 hours of lung allergen exposure and attenuated chemoattractant release and recruitment of PACs by blocking angiogenesis $(27,28)$. HDME exposure increased PAC proliferation and also the mobilization of PACs from the bone marrow. It is possible that these 2 pools of PACs may have different functions. Further studies are needed to assess their potential differences.

Our findings indicate that the lung vascular endothelium has an innate immunity function just like the airway epithelium (6). The airway epithelium has a well-established role in sensing the environment via the expression of various PRRs and connecting the innate and adaptive immunities $(6,7)$. Allergic airway inflammation is triggered by exposure of the airway epithelial cell surface to allergens and is an important source for IL-1 $\alpha$ and GM-CSF in the HDM model of asthma (52). IL-1 $\alpha$ plays a critical role in HDM-induced asthma by activation of dendritic cells (52). Mice deficient for the IL-1 receptor failed to develop a Th2 response or asthma in the HDME model (52). IL-1 $\alpha$ acts in an autocrine way in airway epithelial cells by inducing the release of dendritic cellactivating chemokines GM-CSF, IL-33 (52), and thymic stromal lymphopoietin (TSLP). In airway epithelial cells, IL-1 $\alpha$ controls airway inflammation via epithelial secretion of IL-33 and GMCSF (52). GM-CSF in the lungs has long been associated with Th2 immunity (72-75), and recent reports showed that it is a potent activator of dendritic cells by inducing migration and promoting sensitization of Th $2 \mathrm{CD}^{+} \mathrm{T}$ cells $(52,76)$. Blocking of GM-CSF in the HDME mouse asthma model blunted Th2 responses, including the release of downstream Th2 cytokines (such as IL-4, IL-13, and IL-5) and IgE secretion, resulting in dramatic inhibition of eosinophilic airway inflammation, mucus hyperplasia, and airway hyperresponsiveness $(52,76,77)$. The findings in the present study suggest a similar mechanism of effect in the endothelium.

The concept of an innate vascular response in asthma is supported by a prior report of endothelial activation, as evidenced by increased plasma nitric oxide levels within 4 hours after wholelung allergen challenge in patients with asthma (22). The endothelium in many tissues expresses several members of the PRR family (78), suggesting that endothelial cells are endowed by nature to sense pathogens. The contribution of endothelial innate immune receptors to asthma has been previously unexplored. Here, we showed that the HDM sensing pattern recognition receptor PAR-2 is expressed by naive lung endothelial cells and PACs, and that these angiogenic cells respond by releasing Th2-promoting cytokines and forming new blood vessels.

Overall, our findings reveal that the lung endothelium and PACs have innate capabilities to sense and respond to allergens. This innate Th2-promoting angiogenic response to allergens may have a critical role in allergic asthma origins and it identifies new cellular targets for therapies.

\section{Methods}

Animals. Six- to eight-week-old female WT C57BL/6J or BALB/C mice and PAR-2 ${ }^{-/}$mice were purchased from The Jackson Laboratory. Female Immortomouse animals were purchased from Charles River Laboratories. KLF10 ${ }^{-/-}$mouse bone marrow was provided by Mark Feinberg (Brigham and Women's Hospital, Harvard Medical School).
Imaging and quantification of airway endothelial barrier permeability. Naive C57BL/6J mice were intranasally exposed to HDME (Greer Labs; $20 \mu \mathrm{g} / 50 \mu \mathrm{l}$ saline) (152 ng Der p 1, Greer Labs) for 4 days followed by intranasal administration of HRP $(0.25 \mathrm{mg} / 50 \mu \mathrm{l}$ saline) or low-molecular-weight dextran-FITC (4,000 Da; $12 \mathrm{mg} / 50$ $\mu \mathrm{l})$. In some experiments evaluating the barrier function, animals received HDME by pharyngeal aspiration. Twenty-four hours after HRP administration, animals were euthanized with an overdose of pentobarbital, and lung tissue was stained with DAB and processed by transmission electron microscopy. Samples were fixed by immersion in $2 \%$ glutaraldehyde in $0.1 \mathrm{M}$ phosphate buffer ( $\mathrm{pH} 7.4$ ), and HRP was visualized by treating the sample for 15 minutes with DAB. After a rinse with PBS, tissues were incubated in $1 \%$ osmium tetroxide (in water) for 60 minutes at $4^{\circ} \mathrm{C}$. Samples were washed 2 times with sodium cacodylate for 5 minutes each and rinsed with maleate buffer ( $\mathrm{pH}$ 5.1) once for 5 minutes. Tissues were then stained in $1 \%$ uranyl acetate in maleate buffer for 60 minutes, followed by 3 washes with maleate buffer. Dehydration was performed by incubating tissues in a series of increasing concentrations of ethanol (50\%-95\%, cold and for 5 minutes each), then incubating tissues 3 times in $100 \%$ ethanol (10 minutes each). Tissues were incubated in propylene oxide (3 times, 15 minutes each). Infiltration was performed by removing propylene oxide and adding 1:1 propylene oxide/eponate 12 medium at room temperature overnight, followed by a change to pure eponate 12 medium for 4-6 hours at room temperature. After embedding and polymerization for 24 hours, 85 -nm ultra-thin sections were cut with a diamond knife, stained with uranyl acetate and lead citrate, and then observed with a Tecnai G2 SpiritBT electron microscope operated at $60 \mathrm{kV}$. The integrity of tight junctions was analyzed using electron microscopy as described (79). Animals receiving dextran-FITC were euthanized after 5 hours and blood was drawn by cardiac puncture. Serum samples were quantified for the presence of dextran-FITC using an ELISA reader. Serial dilutions of the stock dextran-FITC solution were used as standard.

In some experiments animals received $20 \mu \mathrm{g} / 50 \mu \mathrm{l}$ saline, $152 \mathrm{ng}$ Der 11 (molecular weight of Der p 1 is $25,000 \mathrm{Da}$ ) for 5 days. One hour after the final dose, mice were anesthetized using pentobarbital and placed on mouse ventilators (Harvard Apparatus; $150 \mu \mathrm{l} /$ stroke at 200 strokes/min). The chest was opened and blood was drawn by cardiac puncture in the left atrium. Plasma was used to quantify Der $p 1$ levels by ELISA (Der p 1 ELISA kit, INDOOR Biotechnologies).

Flow cytometry. Animals were euthanized, and lungs were perfused with warm PBS via the right ventricle to remove all blood cells in the vessels. Identical lung lobes were used within each experiment. Lung tissue was minced and dissociated in $0.1 \%$ collagenase A (Roche Applied Science), 0.04\% DNase I (Sigma-Aldrich), and $0.5 \mathrm{mM} \mathrm{CaCl}$ (Sigma-Aldrich) in $1 \mathrm{ml}$ Dispase II (Roche Applied Science). The number of cells was counted using the TC Automated Cell Counter (Bio-Rad). Single-cell suspension preincubated with Fc block (eBiosciences, catalog 14-0161-81) was stained with the following antibodies: rat anti-mouse CD45-APC (1:100; eBiosciences, catalog 17-0451-82); rat anti-mouse CD31-PE-Cy7 (1:100; eBiosciences, catalog 25-031181); rat anti-mouse CD90.2-V500 (1:200; BD Biosciences, catalog 561616), and rabbit anti-mouse PAR-2 (1:100; Abbiotec Antibodies, catalog 251547). Donkey anti-rabbit FITC (1:100; Jackson ImmunoResearch, catalog 711-096-152) was used a secondary antibody to detect PAR-2 positivity. CD45-PE-Cy5.5 (1:300; eBiosciences, cata- 
A

Intravenous injection with

naive or HDME-exposed PACs

Intranasal sensitization with HDME
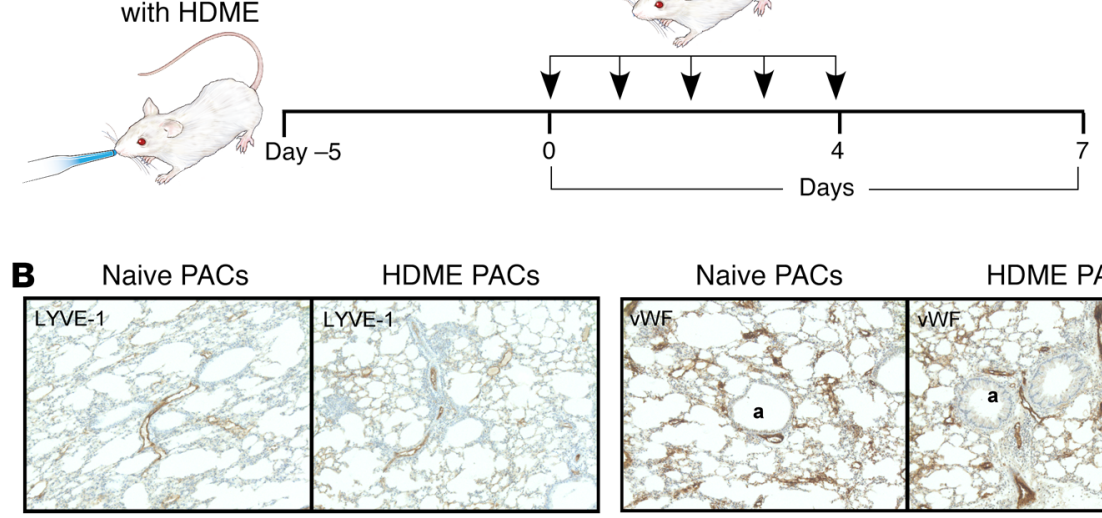

Naive PACs

HDME PACs
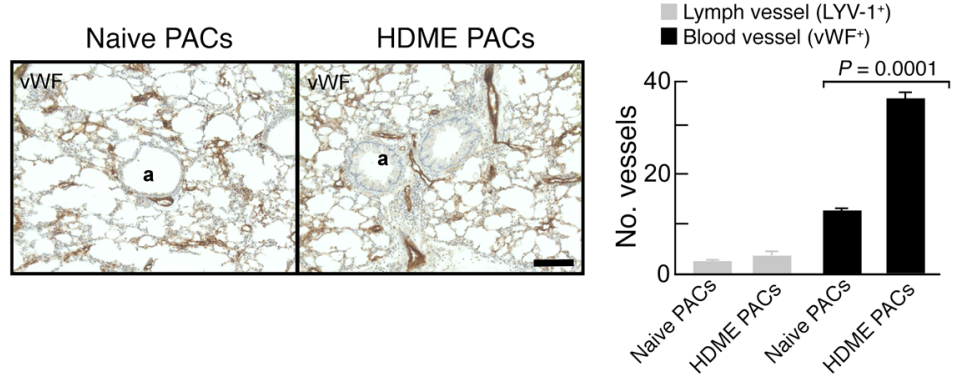

\section{C}
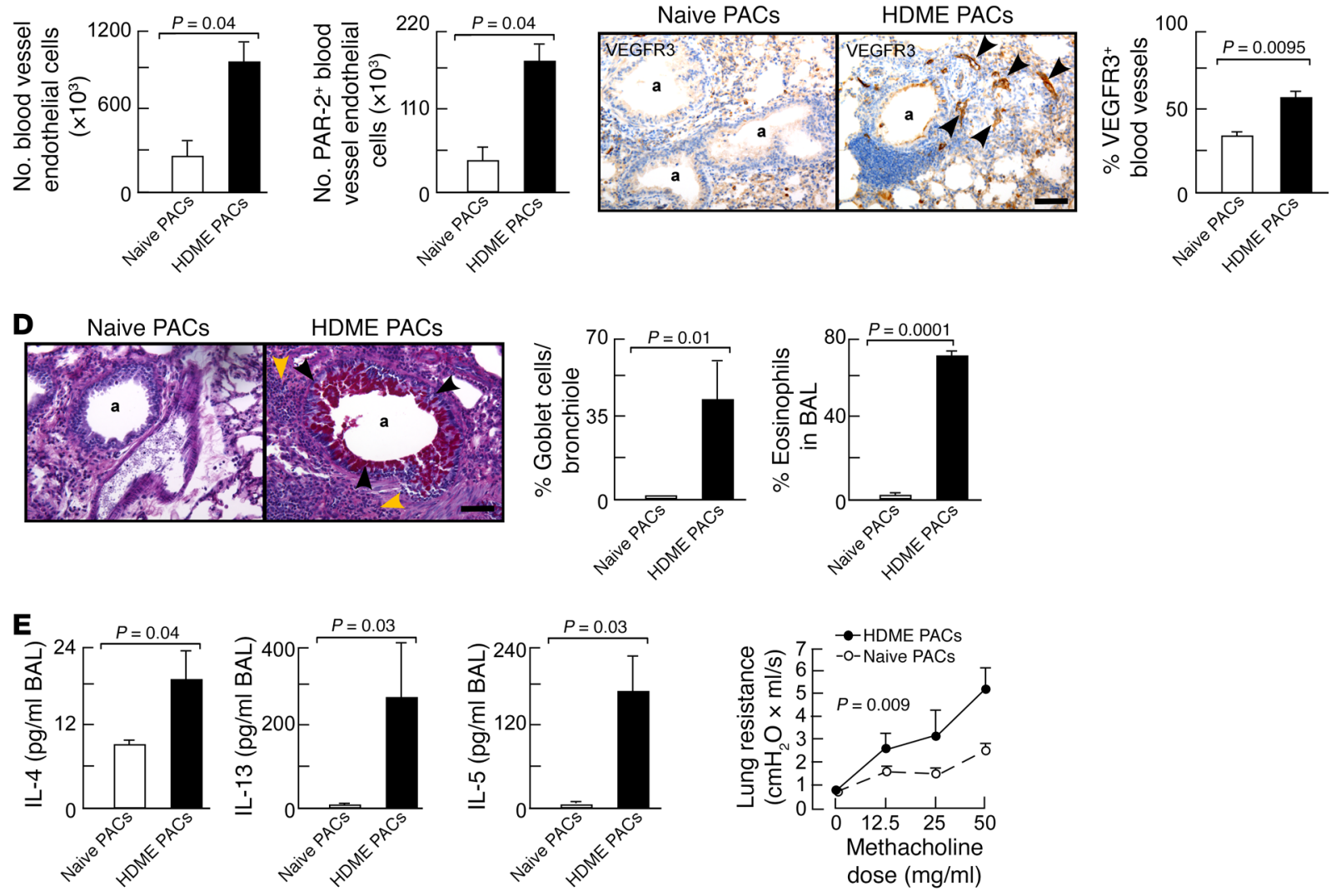
Figure 6. Intravenous adoptive transfer of ex vivo HDME-exposed PACs is sufficient to induce asthma. Bone marrow-derived PACs were ex vivo exposed to HDME and intravenously transferred into HDME-sensitized mice. In contrast to the recipients of naive PACs, animals injected with HDME-exposed PACs developed airway inflammation, remodeling, and hyperreactivity. (A) Schematic overview of ex vivo transfer of PACs into mice. (B) Increased angiogenesis but not lymphangiogenesis in mice injected with HDME-exposed PACs. The number of vessels per 2,500 $\mu \mathrm{m}^{2}$ area is shown. Scale bar, $400 \mu \mathrm{m}$. (C) Angiogenesis and upregulation of PAR-2 and VEGFR3 on endothelial cells in animals receiving naive or HDME-exposed PACs. Number of endothelial cells in identical lung lobes was quantified by flow cytometry using lung single-cell suspension. Blood vessel endothelial cells were defined as CD45-C90-CD31+. VEGFR3 expression was analyzed by immunohistochemistry and number of VEGFR3 ${ }^{+}$ blood cells/field was quantified. (D) Goblet cell metaplasia (black arrows) and eosinophil infiltration (brown arrows) in animals injected with naive or HDME-exposed PACs. (E) Th2 cytokines and airway hyperreactivity in animals receiving naive or HDME-exposed PACs. Mean \pm SE values of 4 mice per group are shown. Scale bar, $100 \mu \mathrm{m}$. Two-tailed Student's $t$ test was used in B, C, D, and $\mathbf{E}$. ANOVA was used in $\mathbf{H}$. A linear regression model was used to compare lung resistance in $\mathbf{E}$. The interaction between group and methacholine dose in the linear mixed effects model for log-transformed values demonstrates that there are differing slopes describing the relationships between methacholine and Rrs for the naive PAC and HDME PAC groups $(P=0.009)$. The estimated slope was 0.033 ( $95 \% \mathrm{Cl} 0.011-0.055)$ for naive PACs and 0.054 (95\% Cl 0.040-0.067) for HDME PACs, indicating a greater change in Rrs in response to methacholine for the HDME PAC group. In all panels, a indicates airway.

$\log$ 35-0451-82) and VEGFR3-biotin (1:200; eBiosciences, catalog 13-5988-82) were used to analyze VEGFR3 expression among lung cells. For the latter application, streptavidin-BV711 (1:800; BD Biosciences, catalog 563262) was used as secondary reagent. Mobilization of PAR-2-expressing PACs was analyzed in the standard HDM model. Blood samples were collected by cardiac puncture and red blood cells were lysed using ammonium chloride. Cell count was performed, followed by staining of Fc-blocked aliquots for SCA-1-APC (1:200; eBiosciences, catalog 17-5981-81); c-Kit-PE (1:200; eBiosciences, catalog 17-5981-82); VEGFR2-APC-Cy7 (1:50; BD Biosciences, catalog 561252), and PAR-2, as described above. Cell proliferation was quantified by staining with anti-mouse Ki-67-PE-eFluor610 (1:200; eBiosciences, catalog 61-5698-82) according to the manufacturer's instructions. All antibodies were titrated to determine optimal staining concentrations. Stainings were performed in a 100- $\mu$ l labeling volume on ice with 30 minutes of incubation time. LIVE/DEAD Fixable Blue Dead Cell Stain Kit (ThermoFisher Scientific) was used according to the manufacturer's instructions to exclude dead cells. Samples were run on an LSRFortessa (BD Biosciences) flow cytometer with standard configuration, and at least 100,000 events were acquired. Data were analyzed using FlowJo 9 software (TreeStar). Fluorescence minus 1 controls were used to set gate boundaries. Cell counts after lung digestion and percentages of subsets obtained by flow cytometry were used to quantify the absolute number of endothelial cells per lung. Cultured PACs were phenotyped for CD45, c-Kit, SCA-1, and VEGFR2 as described $(19,20,22,27,28)$. Gating of PACs in peripheral blood circulation was performed as reported (22).

Isolation of PACs and lung endothelial cells, and in vitro HDME stimulation. PACs were isolated from the bone marrow as described $(19,20)$. Briefly, mononuclear cells obtained by Ficoll separation were plated on fibronectin-coated plates in EGM-2 medium (Lonza), supplemented with $20 \%$ FBS and 20 ng/ml VEGF. After 7 days, floating cells were washed away and the colonies of proliferating PACs were harvested and counted using the TC Automated Cell Counter (Bio-Rad).

Lungs were perfused and digested into single-cell suspension as described above. Dead cells were removed using MACS Dead Cell Removal Kit (Miltenyi Biotec). Viable cells were stained with antimouse CD31-biotin (eBioscience, catalog 13-0311-81) followed by anti-biotin microbead labeling (Miltenyi Biotec, catalog 130-090485 ), and sorted by magnetic activated cell sorting. Obtained endothelial cells were seeded on rat-tail collagen I-coated plates in MCDB-131 complete medium (VEC Technologies). Purity of CD31 $1^{+}$fraction was assessed by flow cytometry analysis and 1,1' -dioctadecyl-3,3,3',3'-tetramethylindocarbocyanine-acetylated LDL (Dil-AcLDL; Molecular Probes) uptake. VEGFR3 expression was analyzed by immunohistochemistry and immunofluorescence.

A quantity of $100 \times 10^{3}$ PACs or lung endothelial cells was incubated with and without HDME $(20 \mu \mathrm{g} / \mathrm{ml}, 152 \mathrm{ng}$ Der p 1/ml) in $0.5 \mathrm{ml}$ medium/24-well for 5 days. Supernatant overlaying the cells was collected and the number of cells was quantified using the TC Automated Cell Counter (Bio-Rad). Levels of IL-1 $\alpha$ and GM-CSF in lung endothelial cell-conditioned medium and VEGF-C in PAC-conditioned medium were quantified using ELISA.

HDME mouse model of asthma. The HDM model was generated as previously described $(51,52)$. Briefly, mice were anesthetized by isoflurane inhalation and intranasally sensitized with $100 \mu \mathrm{g}$ HDME ( $D$. pterronyssinus; Greer Labs) in $50 \mu \mathrm{l}$ saline. Seven days later, animals underwent daily intranasal challenges of $10 \mu \mathrm{g}$ HDME in $50 \mu \mathrm{l}$ saline for 5 days. Four days after the final challenge animals were euthanized for analysis. VEGFR3 was inhibited by daily intraperitoneal treatment with VEGFR3 kinase inhibitor MAZ51 (20 mg/kg body weight; Millipore Sigma) (33). Control groups included HDM-exposed animals treated with vehicle only and naive untreated mice. BAL was collected and processed for ELISA and quantification of eosinophils as previously described $(19,22)$.

ELISA. Mouse GM-CSF, IL-1 $\alpha$, IL-4, IL-13, IL-5, and IgE ELISA kits were purchased from R\&D Systems or Abcam. Mouse VEGF-C ELISA was purchased from MyBioSource.

Immunohistochemistry, immunofluorescence, and histology. Lung endothelial cells were cultured on fibronectin or incubated on angiogenesis gel (in vitro angiogenesis kit, EMD Millipore) in chamber slides for 8 hours, followed by fixation for 10 minutes with $10 \%$ neutral buffered formalin. After 3 washes with PBS, cells were permeabilized and nonspecific binding blocked for 20 minutes with 3.0\% normal goat serum/PBS (Vector Laboratories) containing 0.2\% Triton 100. Cells were washed 3 times with PBS and incubated for 15 minutes with avidin block (Vector Laboratories), followed by 1 PBS wash and 15 minutes of biotin block (Vector Laboratories). Cells were washed with PBS and incubated with primary polyclonal rabbit anti-VEGFR3 (Abcam, catalog ab27278) diluted $1: 100$ in $1.5 \%$ normal goat serum/PBS for 90 minutes at room temperature. Cells were washed 3 times with PBS containing $0.05 \%$ Tween 20 and incubated with Vector Red substrate (Vector Laboratories) diluted as per the manufacturer's instructions for 20 minutes in the dark. Cells were washed 3 times with PBS containing 0.05\% Tween 20 and incubated with FITC-labeled lectin (Griffonia; Sigma) diluted 1:100 in PBS for 45 minutes in the dark. After 3 washes with PBS, slides were mounted with Vectashield Hard Set (Vector Laboratories) with DAPI. All of the above staining with the exception of the 


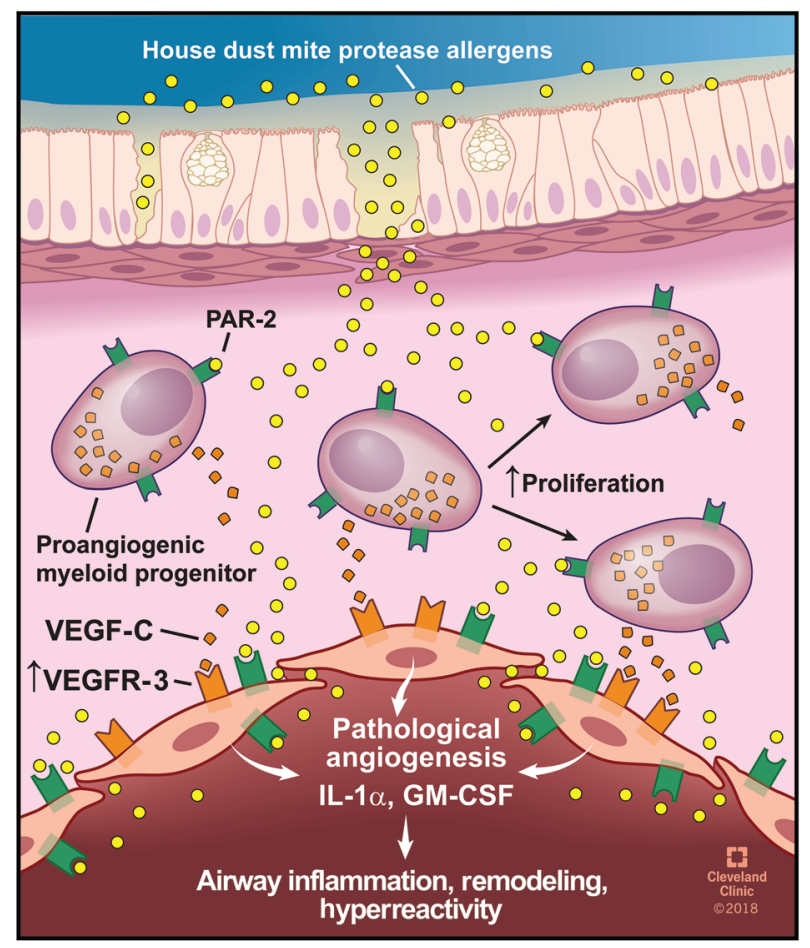

Figure 7. HDM protease allergen sensing by mucosal PACs and endothelial cells. HDM proteases penetrate deep into the airway mucosa where they activate PACs and endothelial cells via PAR-2 binding and induce the release of VEGF-C, GM-CSF, and IL-1 $\alpha$, resulting in airway inflammation, remodeling, and hyperreactivity. Illustration reprinted with the permission of the Cleveland Clinic Center for Medical Art and Photography.

substrate was done with agitation on a rotator. The lectin-only stained slide was processed the same as the others except $1.5 \%$ normal goat serum/PBS (diluent) was applied instead of primary antibody.

Paraffin-embedded lung tissue sections were used for VEGFR3 immunohistochemistry. Staining was performed on a Ventana Benchmark automated immunostainer (Ventana Medical Systems) using a Ventana iVIEW DAB Detection Kit. Primary antibody, rat anti-mouse VEGFR3 (BD Biosciences, catalog 552857) was diluted 1:20, and mild EDTA antigen retrieval was performed. To quantify the percentage of VEGFR3 ${ }^{+}$blood vessels, the number of blood vessels per field was counted in 5 random fields in each sample at a final magnification of $\times 200$ using an Olympus BX40 light microscope.

Mucus staining was performed using periodic acid-Schiff (PAS) staining on paraffin-embedded lung tissue sections. The number of goblet cells per bronchiole was quantified as previously described (19). LYVE-1 immunohistochemistry staining was performed using the Discovery ULTRA automated stainer from Ventana Medical Systems. Antigen retrieval was performed using a citrate-based buffer (Discovery RiboCC, Ventana), pH 6.0, for 8 minutes at $91^{\circ} \mathrm{C}$. Slides were incubated with polyclonal anti-LYVE-1 antibodies (Abcam, catalog ab14917) at a 1:75 dilution for 1 hour at room temperature. The antibody was visualized using the OmniMap anti-rabbit HRP secondary and the ChromoMap DAB detection kit (both from Ventana Medical Systems). Slides were counterstained with hematoxylin and bluing. von Willebrand factor (vWF) staining was performed as described $(21,22)$. There were no significant differences in lung tissue area among groups.
Angiogenesis assays. In vitro, an Angiogenesis Assay Kit (EMD Millipore) was used to study angiogenic tube formation. A quantity of 300 $\times 10^{3}$ lung endothelial cells isolated from Immortomouse (19) in 500 $\mu \mathrm{l}$ MCDB-131 complete medium was seeded in a 12-well angiogenesis gel. HDME or VEGF-C was added at a final concentration of $10 \mu \mathrm{g} /$ $\mathrm{ml}$ or $10 \mathrm{ng} / \mathrm{ml}$, respectively. Cells were incubated at $37^{\circ} \mathrm{C}$ in a $5 \%$ $\mathrm{CO}_{2}$ humidified incubator for 4 hours. Random images of 3 wells were captured at $\times 5$ magnification using an inverted microscope (Leica DM IRB). Network analysis of tube-forming endothelial cells was performed in an automated fashion using customized visual basic macros developed within Image-Pro Plus (v7.0, Media Cybernetics) (22).

Bone marrow transplantation. Animals were sublethally irradiated (total irradiation dose of 1,000 cGy) and injected intravenously with $5 \times 10^{6}$ bone marrow mononuclear cells obtained from PAR-2 ${ }^{-/-}$or $\mathrm{KLF}^{-/-}$mice. Animals with reconstituted bone marrow were used for experiments 4 weeks after the bone marrow transplantation.

Adoptive transfer of PACs. PACs were isolated from the bone marrow of BALB/c mice as described $(19,20)$ and exposed to HDME (Greer Labs; $20 \mu \mathrm{g} / \mathrm{ml}$ ) or saline as described above. After HDME exposure, cells were washed 3 times with warm PBS to remove all HDME. Two-month-old BALB/c recipient mice were intranasally sensitized with HDME $(100 \mu \mathrm{g} / 50 \mu \mathrm{l})$ and after 1 week animals received a daily intravenous injection of naive or HDME-exposed PACs $(800 \times$ $10^{3}$ PACs/mouse) for 5 subsequent days. In some experiments, mice were injected with HDME-exposed bone marrow mononuclear cells depleted of SCA-1 $1^{+}$cells using an anti-Sca- 1 Microbead Kit (Miltenyi Biotec). Seventy-two hours after the final PAC transfer, airway hyperreactivity was measured using FlexiVent (SCIREQ) as described (19).

Statistics. JMP statistical software (SAS Institute) version 13.1.0 was used for statistical analysis. The 2-tailed Student's $t$ test was used for comparison of 2 independent groups. The ANOVA test was used for comparison of 3 independent groups. For airway hyperreactivity, a linear mixed effects regression model for $\log _{2}$-transformed resistance (Rrs), with methacholine dose and an interaction between group and methacholine dose as independent variables, and allowing for an estimated intercept for each mouse, was used to assess whether the slope of a relationship between methacholine dose and $\log _{2}$ Rrs was different between groups. The $\log _{2}$ transformation was used to yield random errors around the model fit that have a distribution better approximated by a normal distribution. Modeling was performed using $\mathrm{R}$ version 3.3.3 (www.R-project.org). $P<0.05$ was considered statistically significant. The specific test for each individual comparison is included in the text or figure legends.

Study approval. All animal experiments were approved by the Cleveland Clinic IACUC in Cleveland, Ohio.

\section{Author contributions}

KA, MY, MA, and SE designed the research studies. KA, KW, KQ, $\mathrm{NW}$, and MY performed the experiments. KA, KW, KQ, NW, and MY acquired data. KA, KW, KQ, NW, and MY analyzed the data. KA, MY, and SE wrote the manuscript.

\section{Acknowledgments}

The authors thank Mark Feinberg (Brigham and Women's Hospital, Harvard Medical School) for providing bone marrow from KLF10-deficient mice; Lerner Research Institute Flow Cytometry Core for excellent assistance with instrument setup and 
quality control; Imaging Core for excellent assistance with tissue processing, immunohistochemistry, and image capture; Matthew Frimel for technical assistance; and Sean Kessler for providing us the protocol to evaluate barrier function using dextran-FITC. The authors also thank Jeff Hammel for assistance with linear regression analysis using R. The illustration in Figure 7 is by David Schumick and is reprinted with permission from the Cleveland Clinic Center for Medical Art and Photography. This work was supported by NIH grants HL103453, HL081064, and HL109250; the Alfred Lerner Memorial Chair in Innovative Biomedical Research at the Cleveland Clinic; and the American Heart Association grant 11SDG4990003.

Address correspondence to: Kewal Asosingh or Serpil Erzurum, Lerner Research Institute, Cleveland Clinic, Department of Inflammation and Immunity, NC22, 9500 Euclid Avenue, Ohio 44195, USA. Phone: 216.445.6625; Email: asosink@ccf.org (K. Asosingh); erzurus@ccf.org (S. Erzurum).
1. Bousquet J, Jeffery PK, Busse WW, Johnson M, Vignola AM. Asthma. From bronchoconstriction to airways inflammation and remodeling. Am J Respir Crit Care Med. 2000;161(5):1720-1745.

2. Davies DE, Wicks J, Powell RM, Puddicombe SM, Holgate ST. Airway remodeling in asthma: new insights. J Allergy Clin Immunol. 2003;111(2):215-225.

3. Ellis A. The pathological anatomy of bronchial asthma. Am JMed Sci. 1908;186(3):407-428.

4. Dunnill MS. The pathology of asthma, with special reference to changes in the bronchial mucosa. J Clin Pathol. 1960;13:27-33.

5. Kuwano K, Bosken CH, Paré PD, Bai TR, Wiggs $\mathrm{BR}$, Hogg JC. Small airways dimensions in asthma and in chronic obstructive pulmonary disease. Am Rev Respir Dis. 1993;148(5):1220-1225.

6. Lambrecht BN, Hammad H. The airway epithelium in asthma. Nat Med. 2012;18(5):684-692.

7. Holgate ST. Innate and adaptive immune responses in asthma. Nat Med. 2012;18(5):673-683.

8. Adam E, et al. The house dust mite allergen Der $\mathrm{p} 1$, unlike Der p 3, stimulates the expression of interleukin-8 in human airway epithelial cells via a proteinase-activated receptor-2-independent mechanism. JBiol Chem . 2006;281(11):6910-6923.

9. Pichavant M, et al. Asthmatic bronchial epithelium activated by the proteolytic allergen Der $\mathrm{p} 1$ increases selective dendritic cell recruitment. J Allergy Clin Immunol. 2005;115(4):771-778.

10. Tomee JF, van Weissenbruch R, de Monchy JG, Kauffman HF. Interactions between inhalant allergen extracts and airway epithelial cells: effect on cytokine production and cell detachment. J Allergy Clin Immunol. 1998;102(1):75-85.

11. Cocks TM, et al. A protective role for proteaseactivated receptors in the airways. Nature. 1999;398(6723):156-160.

12. Cocks TM, Moffatt JD. Protease-activated receptor-2 (PAR2) in the airways. Pulm Pharmacol Ther. 2001;14(3):183-191.

13. Ricciardolo FL, et al. Presence and bronchomotor activity of protease-activated receptor-2 in guinea pig airways. Am J Respir Crit Care Med. 2000;161(5):1672-1680.

14. Schmidlin F, et al. Expression and function of proteinase-activated receptor 2 in human bronchial smooth muscle. Am J Respir Crit Care Med. 2001;164(7):1276-1281.

15. Arizmendi NG, et al. Mucosal allergic sensitization to cockroach allergens is dependent on proteinase activity and proteinaseactivated receptor-2 activation. J Immunol. 2011;186(5):3164-3172.

16. Page K, Ledford JR, Zhou P, Dienger K, Wills-
Karp M. Mucosal sensitization to German cockroach involves protease-activated receptor-2. Respir Res. 2010;11:62.

17. Belting M, et al. Regulation of angiogenesis by tissue factor cytoplasmic domain signaling. $\mathrm{Nat}$ Med. 2004;10(5):502-509.

18. Uusitalo-Jarvinen H, Kurokawa T, Mueller BM, Andrade-Gordon P, Friedlander M, Ruf W. Role of protease activated receptor 1 and 2 signaling in hypoxia-induced angiogenesis. Arterioscler Thromb Vasc Biol. 2007;27(6):1456-1462.

19. Asosingh K, et al. Nascent endothelium initiates Th2 polarization of asthma. J Immunol. 2013;190(7):3458-3465.

20. Asosingh K, Hanson JD, Cheng G, Aronica MA, Erzurum SC. Allergen-induced, eotaxin-rich, proangiogenic bone marrow progenitors: a blood-borne cellular envoy for lung eosinophilia. J Allergy Clin Immunol. 2010;125(4):918-925.

21. Asosingh K, Swaidani S, Aronica M, Erzurum SC. Th1- and Th2-dependent endothelial progenitor cell recruitment and angiogenic switch in asthma. JImmunol. 2007;178(10):6482-6494.

22. Asosingh K, et al. Eotaxin-rich proangiogenic hematopoietic progenitor cells and CCR3+ endothelium in the atopic asthmatic response. J Immunol. 2016;196(5):2377-2387.

23. Vrugt B, Wilson S, Bron A, Holgate ST, Djukanovic R, Aalbers R. Bronchial angiogenesis in severe glucocorticoid-dependent asthma. Eur Respir J. 2000;15(6):1014-1021.

24. Salvato G. Quantitative and morphological analysis of the vascular bed in bronchial biopsy specimens from asthmatic and non-asthmatic subjects. Thorax. 2001;56(12):902-906.

25. Pascual RM, Peters SP. Airway remodeling contributes to the progressive loss of lung function in asthma: an overview. J Allergy Clin Immunol. 2005;116(3):477-486.

26. Huang MT, Dai YS, Chou YB, Juan YH, Wang CC, Chiang BL. Regulatory T cells negatively regulate neovasculature of airway remodeling via DLL4-Notch signaling. J Immunol. 2009;183(7):4745-4754.

27. Imaoka H, et al. Lung homing of endothelial progenitor cells in humans with asthma after allergen challenge. Am J Respir Crit Care Med. 2011;184(7):771-778.

28. Doyle TM, Ellis R, Park HJ, Inman MD, Sehmi R. Modulating progenitor accumulation attenuates lung angiogenesis in a mouse model of asthma. Eur Respir J. 2011;38(3):679-687.

29. Asosingh K, Erzurum SC. Angioplasticity in asthma. Biochem Soc Trans. 2009;37(Pt 4):805-810.

30. Busse PJ, Mathur SK. Age-related changes in immune function: effect on airway inflammation. JAllergy Clin Immunol. 2010;126(4):690-699.

31. Duong HT, Erzurum SC, Asosingh K. Proangiogenic hematopoietic progenitor cells and endothelial colony-forming cells in pathological angiogenesis of bronchial and pulmonary circulation. Angiogenesis. 2011;14(4):411-422.

32. Karkkainen MJ, et al. Vascular endothelial growth factor $\mathrm{C}$ is required for sprouting of the first lymphatic vessels from embryonic veins. Nat Immunol. 2004;5(1):74-80.

33. Tammela T, et al. Blocking VEGFR-3 suppresses angiogenic sprouting and vascular network formation. Nature. 2008;454(7204):656-660.

34. Kaipainen A, et al. Expression of the fms-like tyrosine kinase 4 gene becomes restricted to lymphatic endothelium during development. Proc Natl Acad Sci U S A. 1995;92(8):3566-3570.

35. Laakkonen $\mathrm{P}$, et al. Vascular endothelial growth factor receptor 3 is involved in tumor angiogenesis and growth. Cancer Res. 2007;67(2):593-599.

36. Witmer AN, et al. VEGFR-3 in adult angiogenesis. J Pathol. 2001;195(4):490-497.

37. Valtola R, et al. VEGFR-3 and its ligand VEGF-C are associated with angiogenesis in breast cancer. Am J Pathol. 1999;154(5):1381-1390.

38. Partanen TA, Alitalo K, Miettinen M. Lack of lymphatic vascular specificity of vascular endothelial growth factor receptor 3 in 185 vascular tumors. Cancer. 1999;86(11):2406-2412.

39. Padera TP, Jain RK. VEGFR3: a new target for antiangiogenesis therapy? Dev Cell. 2008;15(2):178-179.

40. Joukov V, et al. A novel vascular endothelial growth factor, VEGF-C, is a ligand for the Flt4 (VEGFR-3) and KDR (VEGFR-2) receptor tyrosine kinases. EMBO J. 1996;15(7):1751.

41. Cao Y, et al. Vascular endothelial growth factor $C$ induces angiogenesis in vivo. Proc Natl Acad Sci US A. 1998;95(24):14389-14394.

42. Witzenbichler B, et al. Vascular endothelial growth factor-C (VEGF-C/VEGF-2) promotes angiogenesis in the setting of tissue ischemia. Am JPathol. 1998;153(2):381-394.

43. Tammela T, et al. VEGFR-3 controls tip to stalk conversion at vessel fusion sites by reinforcing Notch signalling. Nat Cell Biol. 2011;13(10):1202-1213.

44. Heijink IH, van Oosterhout A, Kapus A. Epidermal growth factor receptor signalling contributes to house dust mite-induced epithelial barrier dysfunction. Eur Respir J. 2010;36(5):1016-1026.

45. Wan H, et al. Der 1 facilitates transepithelial allergen delivery by disruption of tight junctions. J Clin Invest. 1999;104(1):123-133. 
46. Kretschmer S, Dethlefsen I, Hagner-Benes S, Marsh LM, Garn H, König P. Visualization of intrapulmonary lymph vessels in healthy and inflamed murine lung using CD90/Thy- 1 as a marker. PLOS ONE. 2013;8(2):e55201.

47. Wara AK, et al. TGF- $\beta 1$ signaling and Krüppel-like factor 10 regulate bone marrow-derived proangiogenic cell differentiation, function, and neovascularization. Blood. 2011;118(24):6450-6460.

48. Wara AK, et al. Bone marrow-derived Kruppellike factor 10 controls reendothelialization in response to arterial injury. Arterioscler Thromb Vasc Biol. 2013;33(7):1552-1560.

49. Rose JA, Erzurum S, Asosingh K. Biology and flow cytometry of proangiogenic hematopoietic progenitors cells. Cytometry A. 2015;87(1):5-19.

50 . Benedito R, et al. The notch ligands Dll4 and Jagged1 have opposing effects on angiogenesis. Cell. 2009;137(6):1124-1135.

51. Plantinga $\mathrm{M}$, et al. Conventional and monocytederived $\mathrm{CD} 11 \mathrm{~b}(+)$ dendritic cells initiate and maintain $\mathrm{T}$ helper 2 cell-mediated immunity to house dust mite allergen. Immunity. 2013;38(2):322-335.

52. Willart MA, et al. Interleukin- $1 \alpha$ controls allergic sensitization to inhaled house dust mite via the epithelial release of GM-CSF and IL-33. J Exp Med. 2012;209(8):1505-1517.

53. Gregory LG, et al. IL-25 drives remodelling in allergic airways disease induced by house dust mite. Thorax. 2013;68(1):82-90.

54. Dumont DJ, et al. Cardiovascular failure in mouse embryos deficient in VEGF receptor-3. Science. 1998;282(5390):946-949.

55. Milia AF, et al. Protease-activated receptor-2 stimulates angiogenesis and accelerates hemodynamic recovery in a mouse model of hindlimb ischemia. Circ Res. 2002;91(4):346-352.

56. Zhu T, et al. Proangiogenic effects of proteaseactivated receptor 2 are tumor necrosis factoralpha and consecutively Tie 2 dependent. Arterioscler Thromb Vasc Biol. 2006;26(4):744-750.

57. Foltin J, Lebowitz H, Boyle PJ. Epithelial tissue. In: Junqueira LC, Carneiro J, eds. Basic Histol- ogy, Tenth Edition. New York, NY: McGrawHill;1902:69-83.

58. Danese S, Dejana E, Fiocchi C. Immune regulation by microvascular endothelial cells: directing innate and adaptive immunity, coagulation, and inflammation. JImmunol. 2007;178(10):6017-6022.

59. Schirbel A, et al. Pro-angiogenic activity of TLRs and NLRs: a novel link between gut microbiota and intestinal angiogenesis. Gastroenterology. 2013;144(3):613-623.e9.

60. Li X, Wilson JW. Increased vascularity of the bronchial mucosa in mild asthma. Am J Respir Crit Care Med. 1997;156(1):229-233.

61. Asokananthan N, et al. House dust mite allergens induce proinflammatory cytokines from respiratory epithelial cells: the cysteine protease allergen, Der $\mathrm{p} 1$, activates protease-activated receptor (PAR)-2 and inactivates PAR-1. JImmunol. 2002;169(8):4572-4578.

62. Sun G, Stacey MA, Schmidt M, Mori L, Mattoli S. Interaction of mite allergens Der $\mathrm{p} 3$ and Der $\mathrm{p} 9$ with protease-activated receptor-2 expressed by lung epithelial cells. J Immunol. 2001;167(2):1014-1021.

63. Schmidlin F, et al. Protease-activated receptor 2 mediates eosinophil infiltration and hyperreactivity in allergic inflammation of the airway. J Immunol. 2002;169(9):5315-5321.

64. Holloway JA, Warner JO, Vance GH, Diaper ND, Warner JA, Jones CA. Detection of house-dustmite allergen in amniotic fluid and umbilicalcord blood. Lancet. 2000;356(9245):1900-1902

65. Wara AK, et al. Bone marrow-derived CMPs and GMPs represent highly functional proangiogenic cells: implications for ischemic cardiovascular disease. Blood. 2011;118(24):6461-6464.

66. McDonald DM. Angiogenesis and remodeling of airway vasculature in chronic inflammation. $A m J$ Respir Crit Care Med. 2001;164(10 Pt 2):S39-S45.

67. Baluk P, Bolton P, Hirata A, Thurston G, McDonald DM. Endothelial gaps and adherent leukocytes in allergen-induced early- and late-phase plasma leakage in rat airways. Am J Pathol. 1998;152(6):1463-1476.
68. Baluk P, et al. Pathogenesis of persistent lymphatic vessel hyperplasia in chronic airway inflammation. J Clin Invest. 2005;115(2):247-257.

69. Moldobaeva A, Jenkins J, Zhong Q, Wagner EM. Lymphangiogenesis in rat asthma model. Angiogenesis. 2017;20(1):73-84.

70. Hooper AT, et al. Engraftment and reconstitution of hematopoiesis is dependent on VEGFR2mediated regeneration of sinusoidal endothelial cells. Cell Stem Cell. 2009;4(3):263-274.

71. Hamrah P, Chen L, Zhang Q, Dana MR. Novel expression of vascular endothelial growth factor receptor (VEGFR)-3 and VEGF-C on corneal dendritic cells. Am J Pathol. 2003;163(1):57-68.

72. Stämpfli MR, et al. GM-CSF transgene expression in the airway allows aerosolized ovalbumin to induce allergic sensitization in mice. J Clin Invest. 1998;102(9):1704-1714.

73. Ohta K, et al. Diesel exhaust particulate induces airway hyperresponsiveness in a murine model: essential role of GM-CSF. J Allergy Clin Immunol. 1999;104(5):1024-1030.

74. Cates EC, et al. Intranasal exposure of mice to house dust mite elicits allergic airway inflammation via a GM-CSF-mediated mechanism. JImmunol. 2004;173(10):6384-6392.

75. Bleck B, Tse DB, Jaspers I, Curotto de Lafaille MA, Reibman J. Diesel exhaust particleexposed human bronchial epithelial cells induce dendritic cell maturation. J Immunol. 2006;176(12):7431-7437.

76. Zhou Q, et al. GM-CSF-licensed CD11b+ lung dendritic cells orchestrate Th2 immunity to Blomia tropicalis. J Immunol. 2014;193(2):496-509.

77. Llop-Guevara A, et al. A GM-CSF/IL-33 pathway facilitates allergic airway responses to subthreshold house dust mite exposure. PLoS One. 2014;9(2):e88714.

78. Takeuchi O, Akira S. Pattern recognition receptors and inflammation. Cell. 2010;140(6):805-820.

79. Goto Y, et al. Dislocation of E-cadherin in the airway epithelium during an antigen-induced asthmatic response. Am J Respir Cell Mol Biol. 2000;23(6):712-718. 